\title{
A Multi-Omics Protocol for Swine Feces to Elucidate Longitudinal Dynamics in Microbiome Structure and Function
}

\author{
Laurin Christopher Gierse ${ }^{1,+}$, Alexander Meene ${ }^{1,+}$, Daniel Schultz ${ }^{2}$, Theresa Schwaiger ${ }^{3}$, \\ Claudia Karte ${ }^{3}$, Charlotte Schröder ${ }^{3}$, Haitao Wang ${ }^{1}{ }^{\mathbb{D}}$, Christine Wünsche ${ }^{1}$, Karen Methling ${ }^{2}$, \\ Bernd Kreikemeyer ${ }^{4}{ }^{\oplus}$, Stephan Fuchs ${ }^{5}$, Jörg Bernhardt ${ }^{1}$, Dörte Becher ${ }^{1}$, Michael Lalk ${ }^{2}{ }^{\mathbb{D}}$, \\ KoInfekt Study Group $¥ \mathbb{1}$, Tim Urich ${ }^{1, *}$ (i) and Katharina Riedel ${ }^{1, *}$ \\ 1 Institute of Microbiology, University of Greifswald, Felix-Hausdorff-Str. 8, 17489 Greifswald, Germany; \\ laurin.gierse@uni-greifswald.de (L.C.G.); alexander.meene@uni-greifswald.de (A.M.); \\ haitao.wang@uni-greifswald.de (H.W.); christine.wuensche@uni-greifswald.de (C.W.); \\ joerg.bernhardt@uni-greifswald.de (J.B.); doerte.becher@uni-greifswald.de (D.B.) \\ 2 Institute of Biochemistry, University of Greifswald, Felix-Hausdorff-Str. 4, 17489 Greifswald, Germany; \\ daniel.schultz@uni-greifswald.de (D.S.); methling@uni-greifswald.de (K.M.); lalk@uni-greifswald.de (M.L.) \\ 3 Friedrich-Loeffler-Institut, Greifswald-Insel Riems, Südufer 10, 17493 Greifswald, Germany; \\ theresa.schwaiger@boehringer-ingelheim.com (T.S.); claudia.karte@fli.de (C.K.); \\ charlotte.schroeder@fli.de (C.S.) \\ 4 Institute for Medical Microbiology, Virology and Hygiene, Rostock University Medical Centre, \\ Schillingallee 70, 18055 Rostock, Germany; bernd.kreikemeyer@med.uni-rostock.de \\ 5 Division of Nosocomial Pathogens and Antibiotic Resistance, Robert Koch Institute Wernigerode, \\ Burgstraße 37, 38855 Wernigerode, Germany; fuchss@rki.de \\ * Correspondence: tim.urich@uni-greifswald.de (T.U.); riedela@uni-greifswald.de (K.R.); \\ Tel.: +49-3834-420-5904 (T.U.); +49-3834-420-5900 (K.R.) \\ + These authors contributed equally to the work. \\ $\ddagger$ Authors of the KoInfekt Study Group were listed in the Author Contributions.
}

Received: 4 September 2020; Accepted: 27 November 2020; Published: 28 November 2020

\begin{abstract}
Swine are regarded as promising biomedical models, but the dynamics of their gastrointestinal microbiome have been much less investigated than that of humans or mice. The aim of this study was to establish an integrated multi-omics protocol to investigate the fecal microbiome of healthy swine. To this end, a preparation and analysis protocol including integrated sample preparation for meta-omics analyses of deep-frozen feces was developed. Subsequent data integration linked microbiome composition with function, and metabolic activity with protein inventories, i.e., $16 \mathrm{~S}$ rRNA data and expressed proteins, and identified proteins with corresponding metabolites. $16 \mathrm{~S}$ rRNA gene amplicon and metaproteomics analyses revealed a fecal microbiome dominated by Prevotellaceae, Lactobacillaceae, Lachnospiraceae, Ruminococcaceae and Clostridiaceae. Similar microbiome compositions in feces and colon, but not ileum samples, were observed, showing that feces can serve as minimal-invasive proxy for porcine colon microbiomes. Longitudinal dynamics in composition, e.g., temporal decreased abundance of Lactobacillaceae and Streptococcaceae during the experiment, were not reflected in microbiome function. Instead, metaproteomics and metabolomics showed a rather stable functional state, as evident from short-chain fatty acids (SCFA) profiles and associated metaproteome functions, pointing towards functional redundancy among microbiome constituents. In conclusion, our pipeline generates congruent data from different omics approaches on the taxonomy and functionality of the intestinal microbiome of swine.
\end{abstract}

Keywords: biomedical model swine; gastrointestinal microbiome; integrated multi-omics; $16 \mathrm{~S}$ rRNA gene-sequencing; metaproteomics; metabolomics 


\section{Introduction}

The microbiome of the human intestinal tract is considered one of the main drivers for host fitness. It is involved in processes such as immune system regulation [1], nutrient utilization [2], and maintenance of intestine function [3]. Changes in the human microbiome were linked to diseases such as obesity [4], type-2 diabetes [5], colorectal cancer [6], Crohn's disease or inflammatory bowel syndrome $[7,8]$. Furthermore, an extrinsic short-term disturbance in the intestinal homeostasis, e.g., by antibiotic treatment, can cause long term disturbance within the commensal intestinal microbiome in a porcine model [9]. Dietary changes also shape the composition of the microbiome [10,11]. Comparison between high-fat/low-fiber (HF) and low-fat/high-fiber (LF) diets revealed a stimulating effect by LF diet on beneficial bacteria (such as Bifidobacterium spp. and Lactobacillus spp.) and the production of short-chain fatty acids (SCFAs). HF content was associated with bacterial groups (e.g., Enterobacteriaceae) with negative impact on human health status, e.g., Escherichia coli and Salmonella enterica.

Addressing the adaptation processes of the human microbiome within the intestinal environment during an infection paves the way to understanding the metabolic impact caused by bacterial and/or viral pathogens. To analyze these changes, there is urgent need for an appropriate in vivo model. Established animal models mainly focus on mice or rats. In particular, mice are widely used as the infection model for the human situation, but the use of this model is hampered by differences between humans and mice in physiology as well as in innate and adaptive immune systems. By comparison of murine and human gastrointestinal anatomy, differences become apparent, for instance the murine cecum is relatively large compared to that of humans. The colon of mice is rather smooth, not divided into different sections (ascending, transverse and descending colon) with a thin muscularis mucosae and without haustrum and taenia coli, in contrast to the human colon [12,13]. It is not only the differing body sizes and lifespans that trigger these differences, but also the occupancy of different ecological niches, resulting in evolution in different environments. Thus, interpretation of preclinical data obtained in mice is difficult [14]. Due to these limitations, alternative model systems to analyze the importance of the intestinal microbiome are required.

Pigs are becoming a popular alternative model organism for research on human health and disease [15]. This is explained by the large similarity between swine and humans in organ size, physiology, genetics, and immune cell populations $[15,16]$. Recently, a swine model with human microbiota was developed to better reflect the human gut [17]. Furthermore, pigs have a typical mammalian composition of the intestinal microbiome dominated by Firmicutes and Bacteroidetes, resembling that of humans $[18,19]$. By taking a deeper look on genus level, the intestinal tract of swine and human share several bacterial groups, such as Prevotella, Faecalibacterium, Coprococcus, Streptococcus, Megasphaera, Dialister and Subdoligranulum, which were absent or very low abundant in the murine intestinal tract [19-21]. In contrast to that, the study of Ley and colleagues of the murine intestinal tract demonstrated that $85 \%$ of the observed bacterial genera were not detected in humans [22]. Dominant and highly prevalent genera of the murine intestinal tract were, for example, Anaerostipes, Parabacteroides and Eggerthella [23]. Higher abundant in mice, but nevertheless prevalent in humans were, for example, Lactobacillus, Turicibacter and Alistipes [13].

Within recent years multi-omics approaches have been applied to answer various scientific questions [24-26]. However, to the best of our knowledge, such an integrated approach has not been used to analyze the gastrointestinal microbiome of swine. Recently, different studies focusing on single omics-approaches to elucidate the intestinal microbiota of swine, e.g., by 16S rRNA gene sequencing $[10,18]$, have been published. Tröscher-Mußotter and colleagues published the first metaproteome analysis highlighting the differences between sections from the small and large intestine of swine [27]. Furthermore, they showed that the relative abundance of proteins involved in energy production and conversion was higher in mucosa than digesta samples. In contrast, proteins involved in lipid transport and metabolism, and short-chain fatty acid production were more abundant in the digesta sample. In spite of that, Tröscher-Mußotter et al. suggested that an integrative approach combining other omics methods would facilitate the understanding of the 
intestinal microbiome [27]. Combination of metaproteomic and metabolomic data allows the prediction of active metabolic pathways [28]. Moreover, metaproteomics have been employed to elucidate the influence of biological factors including disease on taxonomy and function of the microbiome [29-31]. Integrating all the available comprehensive multi-omics technologies constitutes a powerful and promising approach to investigate structure and functionality of gut microbiomes, and provides new insights into host-microbiome relationships within this complex environment that remain hidden when targeting only one single type of molecule.

In the presented study three healthy swine, which served as control group for a 30 day influenza A virus H1N1 infection, were evaluated as baseline for its potential as a biomedical model. Inter-individual variance was of special interest as it could hide infection caused shifts in the respiratory as well as intestinal microbiomes. Our study aimed to (1) establish a standardized, reproducible multi-omics pipeline, including $16 \mathrm{~S}$ rRNA gene sequencing, metaproteomics, and metabolomics analysis, (2) to characterize and monitor the temporal structure and function of the intestinal microbiome of the uninfected animals. Subsequently, this pipeline was used to elucidate the interindividual variability of healthy animals together with the time-dependent progression of the microbiome. Established methodologies and knowledge on the natural development of the swine intestinal microbiome during the experimental time-frame are crucial for further studies elucidating the impact of infections, as well as other interventions or events in the pig's life, on the swine gastrointestinal microbiome.

\section{Materials and Methods}

\subsection{Animal Study Design}

All samples for this study were provided by the Department of Experimental Animal Facilities and Biorisk Management of the Friedrich-Loeffler-Institut on the Isle of Riems within the H1N1pdm09 animal experiment with the reference number 7221.3-1-035/17 [32]. For this study, three mock-infected German landrace pigs, which were eight weeks of age at the beginning of the study, were analyzed. From the third day of their lifes all animals were fed the prestarter diet OlymPig (Agravis, Münster, Germany), for four weeks, additionally to the mother's milk. At the age of four weeks, they were weaned and received a mixture of the OlymPig prestarter and PANTO start (Hamburger Leistungsfutter $\mathrm{GmbH}$, Hamburg, Germany) diet. Afterwards, the animals were fed the PANTO start diet only (24 days before the first sampling day). Both diets were wheat, barley and soy based. Feces were collected from three healthy swine. The sampling scheme is shown in Table 1. Individual fecal samples were collected during or within less than 30 seconds (s) after defecation over a time period of 30 days to cover longitudinal shifts (see feces homogenization and splitting procedure in Figure 1). Furthermore, digesta from intestinal sections (IS) (ileum, proximal and distal colon from three animals) were sampled during necropsy on day 30. All samples were immediately frozen on dry ice and subsequently stored at $-80^{\circ} \mathrm{C}$.

Table 1. Longitudinal sampling scheme and number of samples at each sampling day (d) for meta-omics analysis. Individual samples were collected from three healthy animals.

\begin{tabular}{|c|c|c|c|c|c|c|c|c|c|c|c|}
\hline & & \multicolumn{10}{|c|}{ Days after Starting Point } \\
\hline & & 0 & $2 *$ & $4^{* *}$ & 7 & 14 * & 21 & 22 & 23 & 25 & 30 \\
\hline \multicolumn{2}{|c|}{ Fecal samples $(n=3)$} & 3 & 2 & 3 & 3 & 2 & 3 & 3 & 3 & 3 & 3 \\
\hline \multirow{3}{*}{$\begin{array}{l}\text { Individual number of } \\
\text { analyzed samples after } \\
\text { homogenization }\end{array}$} & 16S rRNA gene analysis & 3 & 2 & 3 & 3 & 2 & 3 & 3 & 3 & 3 & 3 \\
\hline & Metaproteomics & 3 & - & 2 & 3 & - & 3 & - & - & 3 & 3 \\
\hline & Metabolomics & 3 & 2 & 3 & 3 & 2 & 3 & 3 & 3 & 3 & 3 \\
\hline
\end{tabular}

* only two samples were available. ${ }^{* *}$ low amount of sample material from one animal. 


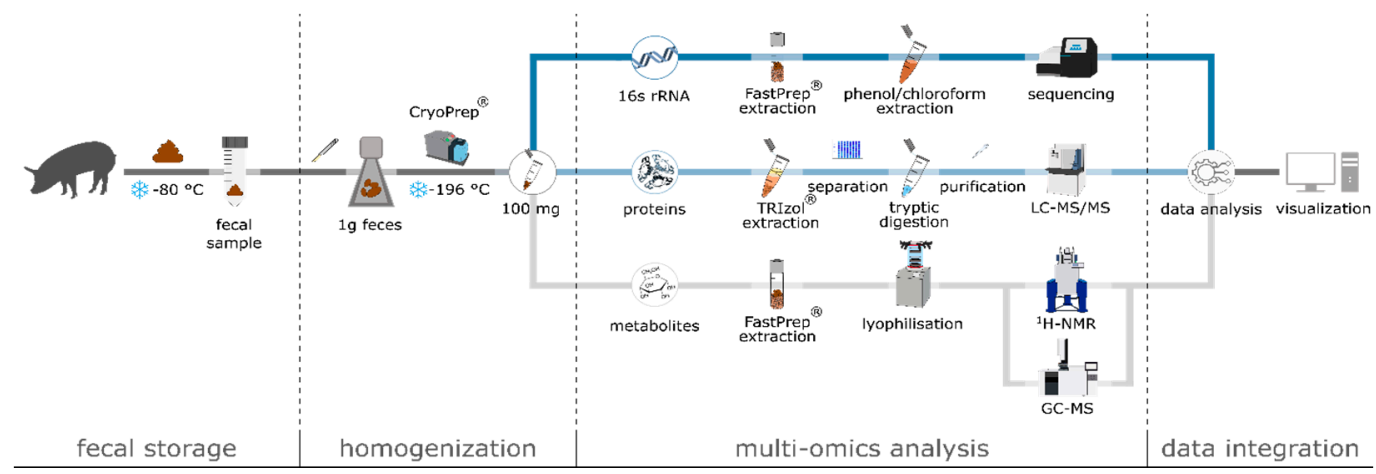

Figure 1. Integrated multi-omics workflow for $16 \mathrm{~S}$ rRNA gene sequencing (blue), metaproteomics (light blue) and metabolomics (grey) out of the same fecal sample. After sampling fecal material was immediately placed on dry ice and stored at $-80^{\circ} \mathrm{C}$, followed by CryoPrep-based homogenization, optimized target-molecule extraction, and analysis, data analysis, integration and visualization.

\subsection{Sample Processing}

The deep-frozen samples were cut with a sterile scalpel to approximately $1 \mathrm{~g}$ pieces and placed into the middle of a Covaris ${ }^{\circledR}$ Tissue Tube ${ }^{\mathrm{TM}}$ TT1. To keep the fecal samples deep-frozen the tissue tube was then placed into liquid nitrogen for $60 \mathrm{~s}$. The Covaris ${ }^{\circledR}$ CP02 CryoPrep ${ }^{\mathrm{TM}}$ instrument (Covaris Ltd., Brighton, UK) was set to impact level 5 and the loaded tissue tube was treated two times with liquid nitrogen for $30 \mathrm{~s}$ between the homogenization steps. The resulting fecal powder was then used for the three different omics-analyses described below.

\subsection{DNA Extraction, $16 S$ rRNA Gene Amplicon Library Preparation, Sequencing, and Bioinformatic Processing}

Nucleic-acids were extracted from the fecal powder by a bead beating phenol-chloroform extraction protocol [33], followed by nucleic acid precipitation with $3 \mathrm{M} \mathrm{Na}$-acetate and isopropanol. After washing with 70\% $v / v$ ethanol the resulting DNA pellets were resuspended in DEPC-treated MilliQ water for downstream applications. DNA content was quantified via Qubit ${ }^{\mathrm{TM}}$ dsDNA Broad Range Assay Kit (Invitrogen ${ }^{\mathrm{TM}}$ ). DNA was diluted to $5 \mathrm{ng} / \mu \mathrm{L}$ for PCR. Amplicon and Index-PCR were performed using the V4 primer pair 515F (5'-GTG-YCA-GCM-GCC-GCG-GTA-A-3')/806R (5'-GGA-CTA-CNV-GGG-TWT-CTA-AT-3') [34,35] followed by a PCR clean up between and after both amplifications with AMPure XP beads. Libraries were quantified via Invitrogen ${ }^{\mathrm{TM}} \mathrm{Qubit}^{\mathrm{TM}} \mathrm{dsDNA}$ broad-range assay kit, normalized to a final concentration of $5 \mathrm{pM}$, denatured with $\mathrm{NaOH}$ and sequenced via Illumina MiSeq with an approximate output from 75,000 to 132,600 reads per sample. The sequences were submitted to European Nucleotide Archive (ENA), with the project number PRJEB39963, accession number ERP123542 and the project name "KoInfekt-multi-omics-pipeline-swine". Resulting 16S rRNA gene sequences were processed in R [36] using the dada2 pipeline-package version 1.11.1 (R-version 3.6.1). Paired-end reads were truncated to a final length of $240 \mathrm{bp}$ each with a minimal overlap of $50 \mathrm{bp}$. Quality-filtered $16 \mathrm{~S}$ rRNA gene sequences $(\operatorname{maxN}=0, \operatorname{maxEE}=2$, and truncQ $=2)$ were clustered to amplicon sequence variants (ASVs), a higher resolution analog of operational taxonomic units (OTUs) [37]. Chimeras were removed and ASVs were assigned via SILVA 132 database [38]. ASVs classified as chloroplasts or mitochondria were removed afterward. Advanced bioinformatic processing (e.g., alpha- and beta diversity, Bray-Curtis dissimilarities and non-metric multidimensional scaling) was performed in R using "vegan", "ggplot", "phyloseq", "plyr", "reshape2" packages. For statistical analysis, PERMANOVA test was performed $(p=0.05)$, using the package "vegan".

\subsection{Protein Extraction and Preparation for Mass Spectrometry}

$1 \mathrm{~mL}$ TRIzol Reagent (Invitrogen, Carlsbad, CA, USA) was added to $100 \mathrm{mg}$ of the homogenized fecal sample and mixed $3 \times 30 \mathrm{~s}$ on a vortex for resuspension. Afterwards, the manufacturer's protocol based on Chomczynski, P. [39] was performed, which comprises the following steps: incubation for 
5 minutes ( $\mathrm{min}$ ), addition of $0.2 \mathrm{~mL}$ chloroform, incubation for $3 \mathrm{~min}$ followed by centrifugation for $15 \mathrm{~min}$ at $12,000 \times \mathrm{g}$ and $4{ }^{\circ} \mathrm{C}$. Subsequently, the aqueous phase was removed, $0.3 \mathrm{~mL}$ ethanol was added and the samples were inverted several times, incubated for another $3 \mathrm{~min}$ and centrifuged for $5 \mathrm{~min}$ at $2000 \times \mathrm{g}$ and $4{ }^{\circ} \mathrm{C}$. The resulting phenol-ethanol supernatant was transferred in new tubes and $1 \mathrm{~mL}$ isopropanol was added. The mixture was incubated for $10 \mathrm{~min}$, centrifuged for $10 \mathrm{~min}$ at $12,000 \times \mathrm{g}$ and $4{ }^{\circ} \mathrm{C}$ to pellet the proteins. The supernatant was discarded. Afterwards, the pellets were washed in $0.2 \mathrm{~mL}$ of $0.3 \mathrm{M}$ guanidine hydrochloride buffer in $95 \%(v / v)$ ethanol, incubated for $20 \mathrm{~min}$, and centrifuged for $5 \mathrm{~min}$ at $7500 \times g$ and $4{ }^{\circ} \mathrm{C}$. The supernatant was discarded. Washing steps were repeated 3 times. $2 \mathrm{~mL}$ ethanol was added to the protein pellets and mixed by vortexing, followed by incubation for $20 \mathrm{~min}$, and centrifugation for $5 \mathrm{~min}$ at $7500 \times \mathrm{g}$ and $4{ }^{\circ} \mathrm{C}$. The supernatant was discarded and the pellets were air-dried. To solve the pellet $200 \mu \mathrm{L}$ of $1 \%(v / v)$ SDS buffer was added. To ensure complete resuspension, the pellet was incubated for $3 \mathrm{~min}$ at $50{ }^{\circ} \mathrm{C}$, and finally centrifuged for $10 \mathrm{~min}$ at $10,000 \times \mathrm{g}$ and $4{ }^{\circ} \mathrm{C}$. The resulting protein extract was transferred to a new tube. Protein concentration was measured by Pierce BCA Protein Assay [40-43].

A quantity of $30 \mu \mathrm{g}$ of the protein extract was separated on a $4-20 \%$ Criterion TGX precast Gel (BioRad, Hercules, CA, USA) and stained with Colloidal Coomassie Brilliant Blue G-250 as published by Neuhoff et al. [44]. Afterwards, each lane was cut in 10 pieces. Each piece was sliced into smaller blocks for tryptic digestion. To this end, gel blocks were destained using a washing solution containing $200 \mathrm{mM}$ ammonium bicarbonate in 30\% $(v / v)$ acetonitrile, incubated in a thermo shaker for $15 \mathrm{~min}$, at $900 \mathrm{rpm}$ and $37^{\circ} \mathrm{C}$. The washing solution was discarded from the tube and the washing step repeated two times. Following destaining, the gel pieces were shrunk to dryness using a vacuum centrifuge. $100 \mu \mathrm{L}$ of a $2 \mu \mathrm{g} / \mu \mathrm{L}$ trypsin stock solution (Promega, Fitchburg, WI, USA) was added to the dried gel-pieces and incubated for $15 \mathrm{~min}$ at RT. Excess trypsin solution was removed and samples incubated overnight at $37^{\circ} \mathrm{C}$. Subsequently, the gel blocks were covered with Aqua Bidest and incubated in an ultrasonic bath for $15 \mathrm{~min}$ to elute the peptides from the gel blocks. The peptide containing supernatant was transferred to new pre-lubricated reaction tubes and desalted using ZipTip purification (C18, Merck Millipore, Billerica, MA, USA) according to the manufacturer's protocol. Afterwards, the peptide mixture was eluted in glass vials, vacuum centrifuged to dryness, resuspended $10 \mu \mathrm{L}$ in $0.1 \%(v / v)$ formic acid, and stored at $-20{ }^{\circ} \mathrm{C}$.

\subsection{Mass Spectrometry Analysis}

The peptide containing solution was applied to an Easy-nLC II with self- packed RP C18 separation column $(100 \mu \mathrm{m}$ i.d $\times 200 \mathrm{~mm}$ length) [45] for reversed-phase chromatography (Thermo Fisher Scientific, Waltham, MA, USA). Peptides were eluted by a binary gradient of buffers A $(0.1 \%(v / v))$ acetic acid and B (99,9\% (v/v) ACN, 0,1\% (v/v) acetic acid) over a time of $100 \mathrm{~min}$ at $300 \mathrm{~nL} / \mathrm{min}$, after loading and desalting them on the column. During analysis injection of the peptide mixture was kept constant. Measurements were performed with an LTQ-Orbitrap-Velos mass spectrometer (Thermo Fisher Scientific, Bremen, Germany) equipped with a nanoelectrospray ion source coupled on-line to the chromatographic system. Samples were measured in data-dependent manner with repeated cycles of overview scans in the Orbitrap (r 30,000) with the lock-mass option enabled, followed by MS/MS acquisition of the 20 most intensive precursor ions in the linear ion trap. Dynamic exclusion was enabled [46]. The mass spectrometry proteomics data have been deposited to the ProteomeXchange Consortium via the PRIDE [47] partner repository with the dataset identifier PXD020775.

\subsection{Database Assembly and Data Analysis}

For protein identification, a specific database for the gastrointestinal microbiome of swine was constructed, based on phylogenetic data obtained from $16 \mathrm{~S}$ rRNA gene sequencing (described above). To this end, all available protein entries of the identified families were downloaded from Uniprot (version 19.11.18). To remove full-length sequence redundancy, the fasta toolkit (fastatk, version 3.0.1, https://gitlab.com/s.fuchs/fastatk) was used. The final database contained 29,366,730 
non-redundant sequence entries. For protein identification raw files were searched against the specific database using the Mascot Daemon version 2.6.0 (Matrix Science Ltd., London, UK) with the following search parameters: enzyme: trypsin; variable modifications, methionine oxidation $(+15.99 \mathrm{Da})$; maximal missed cleavages: 2; peptide charge: $2+, 3+$ and 4+; peptide tolerance $10 \mathrm{ppm}$; MS/MS tolerance $0.5 \mathrm{Da}$. To validate the data, all dat files were applied to Scaffold software version 4.8.7 (Proteome Software Inc., Portland, OR, USA) with the LFDR scoring system and standard protein grouping. Furthermore, X!Tandem was used with a variable modification of methionine (+15.99 Da). Afterwards, a protein threshold of $95 \%$ and 1 peptide per protein were applied to the data. Proteins were considered as identified if they were present in at least two out of the two or three biological replicates. If identical peptides occur in different proteins and these proteins could not be discriminated by the MS/MS analysis they were assigned to one protein group.

\subsection{Taxonomic, Functional and Statistical Analysis of Protein Groups}

Taxonomic and functional protein analysis was performed using the metaproteome annotation pipeline Prophane (www.prophane.de). For taxonomic analysis, Prophane used diamond blast combined with the NCBI nr protein database (version 08.08.2018) with an e-value of 0.01, query-coverage of 0.9 , and max-target-seqs of 1 . For the comparison of protein and $16 \mathrm{~S}$ rRNA derivated taxonomic classification data, NCBI taxonomy was manually transcribed to SILVA taxonomy. Functional annotation was performed using the hmmscan algorithm combined with TIGRFAMs (version 16.09.2014) and eggNOG database (version 4.5.1) applying an e-value of 0.01. For statistical analysis, data was z transformed and a one-sample ANOVA test was performed ( $p$-value 0.05 ) using $\mathrm{MeV}$ [48].

\subsection{Extraction of Metabolites}

$100 \mathrm{mg}$ of frozen feces powder was transferred in a FastPrep ${ }^{\mathrm{TM}}$ tube (containing lysing matrix $\mathrm{E}$ (MP Biomedicals ${ }^{\mathrm{TM}}$, Eschwege, Germany) and $2 \mathrm{~mL} \mathrm{80 \%} \mathrm{methanol} \mathrm{and} 400 \mu \mathrm{L}$ internal standard was added. Powder was disrupted two times for $40 \mathrm{~s}$ with $5.5 \mathrm{~m} / \mathrm{s}$ followed by centrifugation $(12,400 \times g$, $10 \mathrm{~min}, 4^{\circ} \mathrm{C}$ ). The supernatant was transferred into a new tube on ice and the FastPrep ${ }^{\mathrm{TM}}$ treatment was repeated once with ice-cold water and $500 \mu \mathrm{L}$ dichloromethane and once with $2 \mathrm{~mL}$ ice-cold water. All supernatants were combined, vortexed, and stored for $10 \mathrm{~min}$ on ice. After centrifugation, the water/methanol containing phase was lyophilized. The lyophilized samples were resuspended in $1 \mathrm{~mL}$ water and split into two samples for subsequent GC-MS and ${ }^{1} \mathrm{H}-\mathrm{NMR}$ analysis.

\subsection{Analysis of Metabolites Using GC-MS and ${ }^{1} H-N M R$}

For GC-MS analysis, the lyophilized extracts were derivatized and measured as previously described in Schultz et al., 2017 [49]. Details on GC-MS parameters are described in Dörries et al., 2014 [50]. Metabolites were absolutely quantified using calibration curves from standards or relative amounts were calculated using ribitol as internal standard with ChromaTOF ${ }^{\circledR}$ V4.508.0 software. Metabolite identification was done by using standard compounds. For ${ }^{1} \mathrm{H}-\mathrm{NMR}$ analysis, the samples were resuspended in $500 \mu \mathrm{L}$ PBS, vortexed, and metabolites in the supernatant were measured with a Bruker ${ }^{\circledR}$ Avance II 600 NMR spectrometer according to Schultz et al., 2017 [49]. In total, 70 different metabolites per fecal sample and time point (Figure S1) were detected by standard compounds.

\subsection{Swine Feces Processing Pipeline Suitable for Multi-Omics Analyses}

We compiled several individual steps from the above described methods into a feces processing pipeline suitable for multi-omics analyses (Figure 1). We highlight several of the important steps and considerations. The fecal samples were snap-frozen on dry ice immediately after collection and kept frozen at $-80{ }^{\circ} \mathrm{C}$ until homogenization and extraction to prevent metabolite and protein degradation. Especially for metabolites, but also for metaproteome analysis, an immediate quenching 
of protein biosynthesis and metabolism as well as constant storage at $-80{ }^{\circ} \mathrm{C}$ is of utmost importance [51-53]. Moreover, swine feces appear to be a highly heterogeneous sample matrix, e.g., due to incorporated indigestible fibers, which can affect the local composition of the microbiome. Therefore, proper feces homogenization prior to extraction of DNA, proteins and metabolites is crucial for generating representative data sets of microbiome composition and functionality. Different methods for homogenization were tested including (i) grinding of frozen samples with mortar and pestle, (ii) suspending samples in water, (iii) grinding thawed samples via bead mill, as well as (iv) pulverization of frozen samples via CryoPrep (data not shown). Due to the practicability of the tested homogenization methods, the best results were achieved employing the CryoPrep protocol as described in previous studies with different sample materials [54].

\section{Results and Discussion}

\subsection{Multi-Omics Analyses of Swine Feces}

The established protocol (see above Section 2.10) enables an effective, contamination-free homogenization of frozen fecal samples for subsequent integrated analysis of $16 \mathrm{~S}$ rRNA gene sequencing, metaproteomics and metabolomics (Figure 1). Notably, only $300 \mathrm{mg}$ of homogenized feces were required for this approach.

16S rRNA gene analysis. DNA from homogenized feces was extracted using an extraction protocol based on bead beating and phenol/chloroform [33], yielding approx. $130 \mu \mathrm{g}$ DNA/g feces. TRIzol-based extraction resulted in much lower DNA yields (Table S1). Illumina Miseq amplicon sequencing of the V4 region of the $16 \mathrm{~S}$ rRNA gene resulted in overall 1040 unique bacterial and archaeal ASVs, with rather uniform richness dynamics over time and a remarkably low variability between the individual fecal microbiomes (Table 2).

Notably, although richness and diversity were found to be highest on day 25 , these parameters stayed relatively constant during the study period. The protocol resulted in an observed average richness of the samples of 820 ASVs $( \pm 105$ ASVs, CV $=0.13)$ an average Shannon index of $5.17( \pm 0.15$, $\mathrm{CV}=0.028)$ and an average Evenness of $0.77( \pm 0.011, \mathrm{CV}=0.015)$. These values were similar or higher as compared to other findings from swine fecal microbiomes [19]. Applying rectal swabs in a longitudinal experiment over 174 days, Wang and colleagues [55] detected up to 500 phylotypes. A fluctuation in richness was observed that depended on dietary changes. A meta-study of microbiomes from porcine GI tract and fecal samples identified 558 core OTUs [20]. This indicates a comparable microbiome diversity obtained with the presented multi-omics sample processing approach.

Metaproteomics: Initially, different extraction protocols, including a chloroform-based protocol for sewage sludge [56], an urea/thiourea-based protocol for microbial biofilms [46], a protocol combining heating and bead-beating [57], and a TRIzol-based protocol, were tested for efficiency (Table S2). The TRIzol-based protocol appeared to be most promising yielding approximately $8 \mathrm{mg}$ protein per $\mathrm{g}$ feces on average and resulting in a mean of $4189( \pm 401)$ protein groups (PGs) identified in 2 of 2 or 3 biological replicates for each individual sample consisting of $100 \mathrm{mg}$ feces (Table 3). The large majority of the identified PGs were of bacterial origin (average 91\%), followed by eukaryotic PGs (Table S3). The number of identified PGs is significantly higher than in other comparable studies on fecal samples (e.g., $[11,25,27])$ although the processed amount of biomass was lower. This might be explained by the use of 10 fractions instead of 1 or 3 fractions from one gel band after 1D SDS PAGE for mass spectrometry analysis. Tröscher-Mußotter and colleagues [27] identified a mean of 1780 PGs ( \pm 153$)$ from $5 \mathrm{~g}$ of colon digesta. The study of Heinritz and colleagues [11] resulted in 500 to 740 PG identifications from $300 \mathrm{mg}$ of swine feces. In an integrated multi-omics study of Heintz-Buschart and colleagues [25], focusing on the intestinal microbiome of humans with type 1 diabetes, a mean of $2573( \pm 1645)$ PGs has been identified from $200 \mathrm{mg}$ stool samples. 
Table 2. Microbiome alpha-diversity parameters. Average, standard deviation and coefficient of variance (CV) of richness (number of ASVs), Shannon, and Simpson index of the fecal microbiota sampled from healthy piglets along the experiment.

\begin{tabular}{|c|c|c|c|c|c|c|c|c|c|c|}
\hline & \multicolumn{10}{|c|}{ Days after Sampling } \\
\hline & 0 & 2 & $4^{*}$ & 7 & $14^{*}$ & 21 & 22 & 23 & 25 & 30 \\
\hline $\begin{array}{l}\text { No. of ASVs } \pm \text { sd; } \\
\text { CV }\end{array}$ & $\begin{array}{c}831 \pm 97 \\
0.12\end{array}$ & $\begin{array}{c}716 \pm 112 \\
0.16\end{array}$ & $\begin{array}{l}773 \pm 36 \\
0.05\end{array}$ & $\begin{array}{l}816 \pm 169 \\
0.21\end{array}$ & $\begin{array}{l}859 \pm 161 \\
0.19\end{array}$ & $841 \pm 88 ; 0.1$ & $828 \pm 80 ; 0.1$ & $\begin{array}{l}857 \pm 161 \\
0.19\end{array}$ & $\begin{array}{c}901 \pm 99 \\
0.11\end{array}$ & $\begin{array}{l}780 \pm 47 \\
0.06\end{array}$ \\
\hline $\begin{array}{c}\text { Shannon } \pm \text { sd; } \\
\text { CV }\end{array}$ & $\begin{array}{l}5.19 \pm 0.10 \\
\quad 0.02\end{array}$ & $\begin{array}{l}5.00 \pm 0.12 \\
\quad 0.02\end{array}$ & $\begin{array}{l}5.10 \pm 0.13 \\
\quad 0.02\end{array}$ & $\begin{array}{c}5.30 \pm 0.26 \\
0.05\end{array}$ & $\begin{array}{c}5.26 \pm 0.23 \\
0.04\end{array}$ & $\begin{array}{c}5.14 \pm 0.17 \\
0.03\end{array}$ & $\begin{array}{l}5.13 \pm 0.13 \\
0.03\end{array}$ & $\begin{array}{c}5.23 \pm 0.13 \\
0.03\end{array}$ & $\begin{array}{c}5.40 \pm 0.14 \\
0.03\end{array}$ & $\begin{array}{l}5.02 \pm 0.05 \\
\quad 0.01\end{array}$ \\
\hline $\begin{array}{l}\text { Simpson } \pm \text { sd; } \\
C V\end{array}$ & $\begin{array}{l}0.99 \pm 0.001 \\
0.001\end{array}$ & $\begin{array}{l}0.98 \pm 0.003 \\
0.004\end{array}$ & $\begin{array}{l}0.99 \pm 0.002 \\
0.002\end{array}$ & $\begin{array}{l}0.99 \pm 0.003 \\
0.003\end{array}$ & $\begin{array}{l}0.99 \pm 0.003 \\
0.003\end{array}$ & $\begin{array}{l}0.98 \pm 0.003 \\
0.03\end{array}$ & $\begin{array}{l}0.98 \pm 0.003 \\
0.003\end{array}$ & $\begin{array}{l}0.98 \pm 0.003 \\
0.003\end{array}$ & $\begin{array}{l}0.99 \pm 0.001 \\
0.001\end{array}$ & $\begin{array}{l}0.98 \pm 0.002 \\
0.002\end{array}$ \\
\hline $\begin{array}{c}\text { Evenness } \pm \text { sd; } \\
\text { CV }\end{array}$ & $\begin{array}{l}0.77 \pm 0.006 \\
0.007\end{array}$ & $\begin{array}{l}0.76 \pm 0.001 \\
\quad 0.001\end{array}$ & $\begin{array}{l}0.77 \pm 0.021 \\
0.027\end{array}$ & $\begin{array}{l}0.79 \pm 0.015 \\
\quad 0.019\end{array}$ & $\begin{array}{l}0.78 \pm 0.013 \\
0.016\end{array}$ & $\begin{array}{l}0.76 \pm 0.013 \\
\quad 0.017\end{array}$ & $\begin{array}{l}0.76 \pm 0.009 \\
\quad 0.012\end{array}$ & $\begin{array}{l}0.78 \pm 0.016 \\
\quad 0.021\end{array}$ & $\begin{array}{l}0.79 \pm 0.011 \\
0.013\end{array}$ & $\begin{array}{l}0.75 \pm 0.012 \\
0.016\end{array}$ \\
\hline
\end{tabular}

${ }^{*}$ samples from only two individuals were available. 
Table 3. Protein groups identified from porcine feces including total and unique (per biological replicate) numbers of PGs from individual swine feces samples at the corresponding sampling days as well as numbers of PG identified in at least 2 of 3 biological replicates.

\begin{tabular}{ccccccc}
\hline & \multicolumn{5}{c}{ Days after Sampling } \\
\cline { 2 - 7 } & 0 & $4^{*}$ & 7 & 21 & 25 & 30 \\
\hline Pig 1 & 5228 & & 6215 & 5038 & 4224 & 4886 \\
unique & 1091 & & 2653 & 1279 & 960 & 1108 \\
Pig 2 & 5342 & 6920 & 3672 & 5274 & 5450 & 6101 \\
unique & 1231 & 3303 & 1059 & 1458 & 2068 & 2217 \\
Pig 3 & 6271 & 5686 & 4837 & 5022 & 5204 & 5298 \\
unique & 2052 & 2069 & 1539 & 1601 & 1842 & 1289 \\
In 2 of 3 & 4797 & 3617 & 3882 & 4380 & 3970 & 4491 \\
\hline \multicolumn{7}{c}{ * only two biological replicates available. }
\end{tabular}

Metabolomics: The homogenous fecal powder was applied to a FastPrep cell disruption followed by water/methanol/dichloromethane metabolite extraction. Different amounts of extraction volume and lysing matrices were tested. The best results were obtained using lysing matrix $\mathrm{E}$ and a total extraction volume of $6.5 \mathrm{~mL}$ water/methanol/dichloromethane (data not shown). In total, 70 different metabolites per fecal sample and time point (Figure S1) were detected, which is in good accordance with other studies focusing on feces analysis by GC-MS and NMR analysis [51,58,59]. We focused on primary metabolites, i.e., amino acids and related degradation intermediates, carbon core metabolites, fatty acids, and SCFA (Table 4). These metabolites, mainly SCFA, were also analyzed in other studies focusing on swine fecal metabolome [60-62].

Table 4. Classification of detected metabolites into main metabolic pathways.

\begin{tabular}{cc}
\hline Pathway & Number of Detected Metabolites \\
\hline carbon core metabolism & 13 \\
amino acids & 18 \\
amino acid degradation & 6 \\
fatty acids & 6 \\
short-chain fatty acids & 6 \\
various & 21 \\
$\Sigma$ & 70 \\
\hline
\end{tabular}

Compared to other meta-omics studies, in which the amount of samples ranged from $150 \mathrm{mg}$ to $5 \mathrm{~g}[11,25,27,63,64]$, our protocol is based on a rather small amount of sample material, i.e., a minimum of 40,80 , and $100 \mathrm{mg}$ for $16 \mathrm{~S}$ rRNA gene sequencing, metaproteomics, and metabolomics, respectively, enabling integrated multi-omics analyses of low biomass samples.

\subsection{Taxonomic Composition of the Intestinal Microbiome}

Determination of microbiome composition was performed at 16S rRNA gene level, representing prokaryotes, both active and dormant, and at metaproteome level, indicative of active prokaryotes. In general, $16 \mathrm{~S}$ rRNA gene and metaproteome profiles were similar and revealed a typical mammalian fecal microbiome consisting primarily of Firmicutes and Bacteroidetes (Figure 2) [19,65]. Furthermore, all three biological replicates at each timepoint were comparable with similar temporal dynamics. We identified the family Prevotellaceae as predominant (approx. $20 \%$ of $16 \mathrm{~S}$ rRNA genes and up to $\approx 30-35 \%$ in metaproteome), which was also described by Heinritz and colleagues [11]. Besides Prevotellaceae the families Lactobacillaceae, Lachnospiraceae, Veillonellaceae, and Clostridiaceae showed similar variation over time based on $16 \mathrm{~S}$ rRNA gene sequencing and metaproteomic data. Confirming a previous finding [66], we observed a time-dependent decrease of Lactobacillaceae. On metaproteome level, the increasing abundances in Prevotellaceae at d7, as well as in Spirochaetaceae 
and Streptococcaceae on d21 were directly correlated with the decrease in Lactobacillaceae. When the Lactobacillaceae recovered, the previously mentioned families started to decrease. Generally, the observed longitudinal dynamics in the taxonomic composition of microbiomes of $16 \mathrm{~S}$ rRNA genes and protein groups were reflected in the nonmetric multidimensional scaling (NMDS) analyses (Figure 3A,B, Table S4). Here, the positions of the intermediate time points (d7-d25) formed clusters in close proximity to each other, and separated from the early ( $\mathrm{d} 0$ and $\mathrm{d} 2$ ) timepoints (Figure $3 \mathrm{~A}$ ) and from the early ( $\mathrm{d} 0$ and $\mathrm{d} 4$ ) and late (d30) timepoints (Figure 3B). Temporal dynamics of the active microbiome over a 30-day experiment were expected in the eight weeks old piglets [55], however this intermediate shift in microbiome composition was not anticipated. Interestingly, we detected Methanobacteriaceae primarily at $16 \mathrm{~S}$ rRNA gene level, but with much lower abundance in the metaproteome. This discrepancy might have been caused by primer bias and/or low identification rate for archaeal proteins in the metaproteome analysis. Furthermore, the observed variation can be explained on a biological level, regarding the different copy numbers of $16 \mathrm{~S}$ rRNA genes in different species [67]. The large difference in the relative abundance of Ruminococcaceae between $16 \mathrm{~S}$ rRNA and the taxonomic metaproteome analysis can be explained by the LCA algorithm used for the taxonomic assignment of the PGs, since many PGs of Clostridiales cannot be reliably classified on family level as Ruminococcaceae, thus these PGs remain classified as 'various'. Nevertheless, the described taxonomic similarities between 16S rRNA gene and metaproteome level underline the reliability of the presented approach. Nevertheless, the described taxonomic similarities between 16S rRNA gene and metaproteome level, e.g., the appearance of Streptococcaceae at day 21, and the time dependent variation of Lactobacillaceae and Spirochaetaceae abundance underline the reliability of the presented approach.

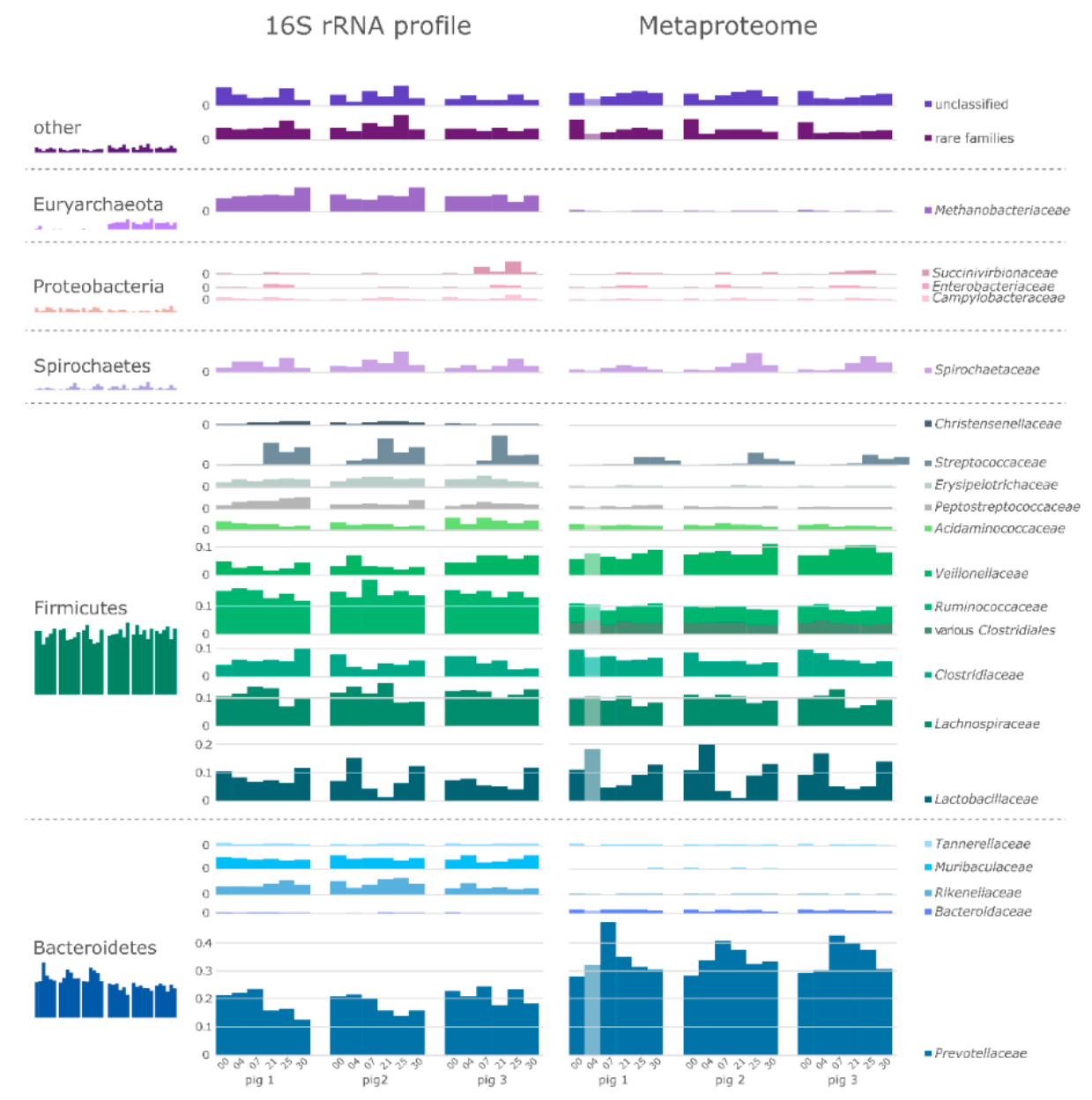

Figure 2. Dynamic development of the fecal microbiota from three healthy swine over 30 days. Comparison of the relative abundances based on $16 \mathrm{~S}$ rRNA gene and metaproteome data on phylum 
level (small barplots, left) and family level. For better illustration, only families above $1 \%$ of the relative amount were shown. SILVA taxonomy was used for this comparison.
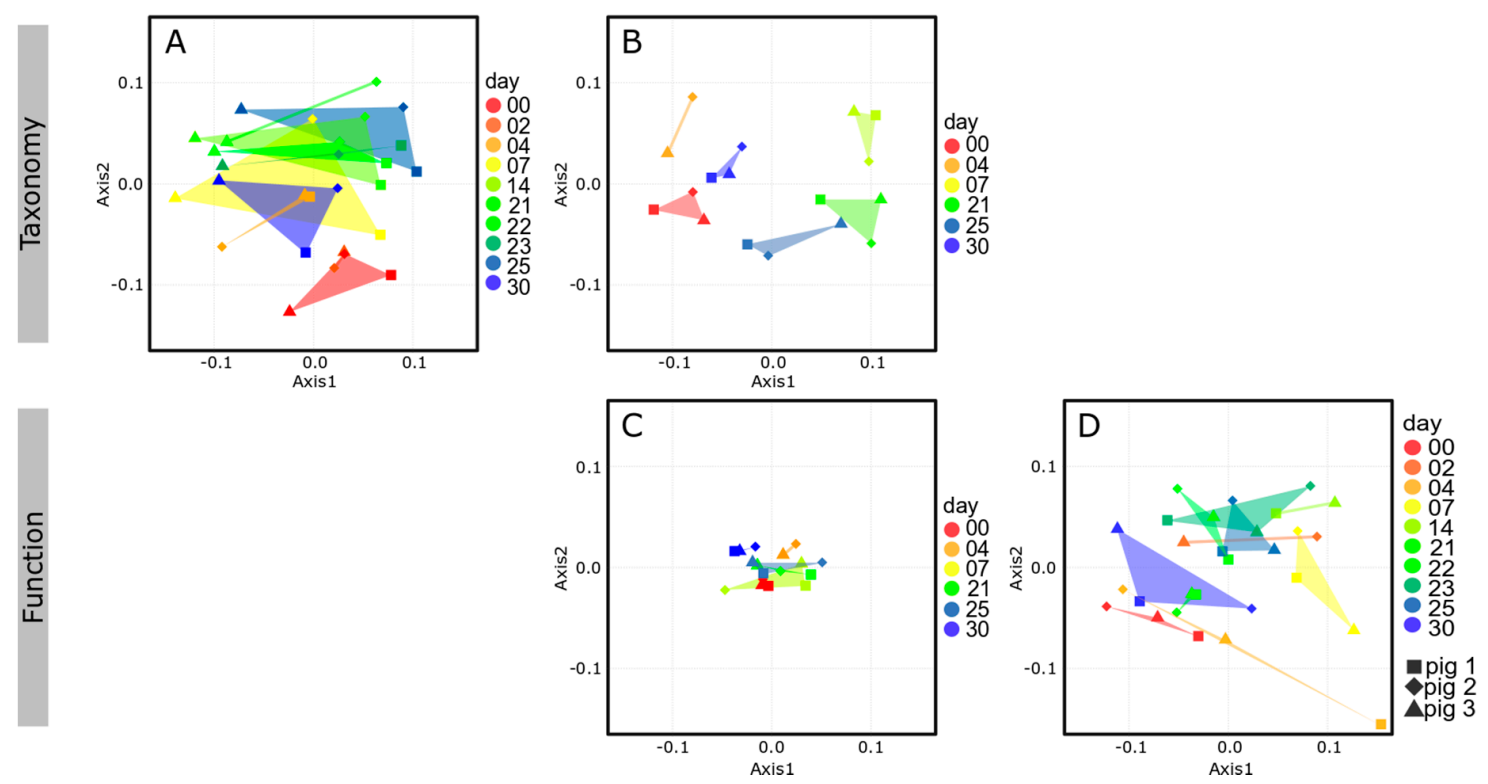

Figure 3. Nonmetric multidimensional scaling (NMDS) plots, based on Bray-Curtis dissimilarities, of the 16S rRNA gene profile (A), metaproteome taxonomy (B), and function (C) and the metabolome (D). NMDS plots revealed similar tendencies on taxonomic level $(\mathbf{A}, \mathbf{B})$ as well as on functional level (C,D).

High Similarity of the Fecal and Colonal Microbiota

Using 16S rRNA gene amplicon sequencing, we tested if the microbiome composition of feces can serve as a reliable minimal-invasive proxy for the intestinal microbiome composition. Looft and colleagues indicated limited transferability of fecal microbiomes compared to microbiomes of the intestinal tract, due to the low number of reference studies [68].

We compared microbiomes from feces with the corresponding microbiomes from distal and proximal colon lumen, and from ileum (Figure 4, Table S5). While we saw a high accordance of the two colonal microbiomes with the fecal microbiome (without significant differences), the microbiome from ileal samples differed strongly (e.g., ileum vs. proximal colon $p=0.006)$. Furthermore, richness data indicate a high significant difference between the merged fecal- and colonal richness and the one from ileum $(p=0.001)$. The large intestine is primarily dominated by Prevotellaceae, Ruminococcaceae, Lachnospiraceae, and Lactobacillaceae, whereas the most abundant families in the ileum are Clostridiaceae, Erysipelotrichaceae and Peptostreptococcaceae. This is likely due to the higher transition rates in the ileum. In the study of Deusch and colleagues [69] the fecal microbiome was also compared to intestinal microbiomes (ileum and colon) of livestock. Similar to our results, the colonal and fecal microbiomes showed a more similar composition than with the ileal microbiomes. The opportunity of taking feces as proxy for the large intestine could pave the way for (simple) predictions of the intestinal status with "minimal-invasive" sampling techniques, thus enabling follow-up of the same individuals over a longer period of time without the need for additional animals that have to be sacrificed during the experimental trial. 


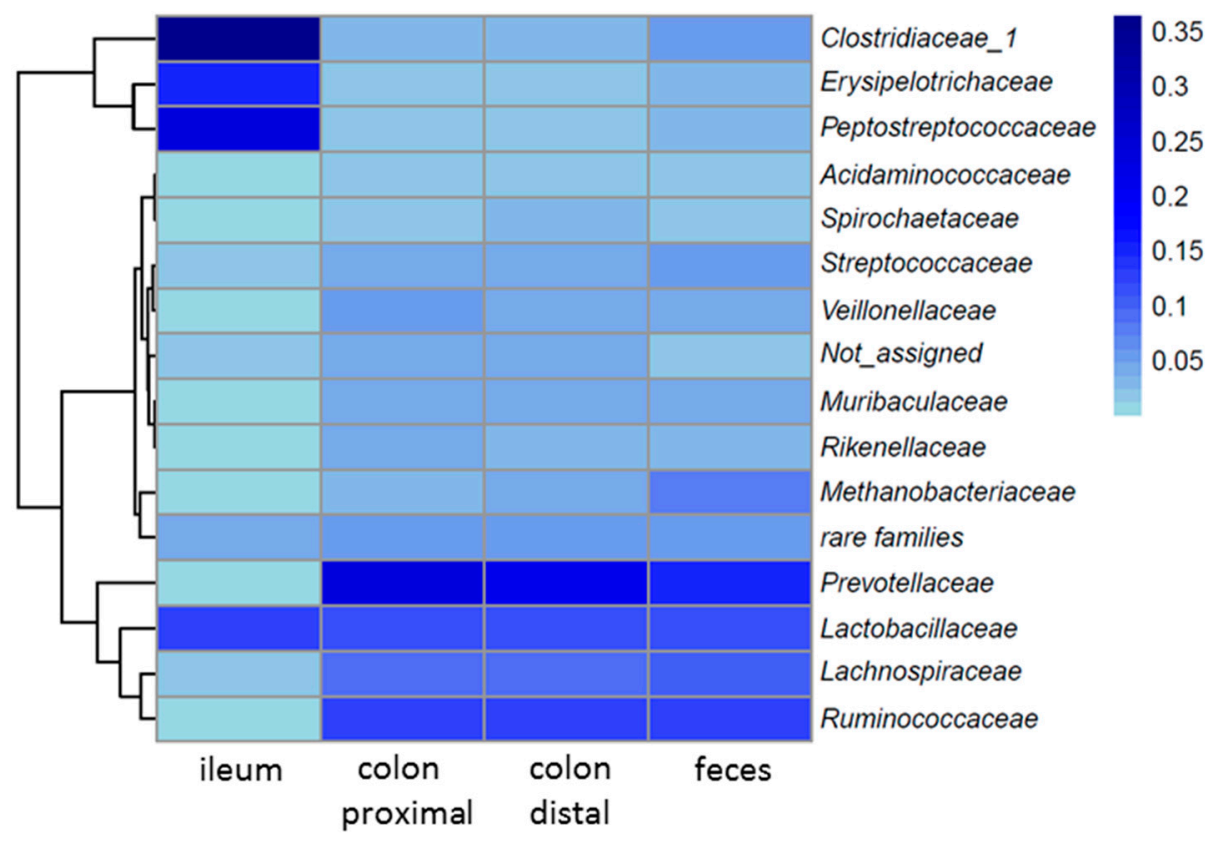

Figure 4. Fecal community of swine 1, 2, and 3 (merged) composition and comparison between the intestinal samples on family level. Color code from light blue to dark blue indicates an increasing relative abundance.

\subsection{Functional Analysis of the Microbiome}

Functional assignment of the identified PGs (see Materials and Methods) revealed a similar distribution for all metaproteomes at the qualitative level during the entire course of the experiment (Figure 5). More than 65\% of the identified PGs were assigned to specific biological functions, which is in good accordance to the ratio of described functional annotations of the employed eggNOG database [70]. A proportion ranging from $25 \%$ to $30 \%$ of the PGs were involved in protein biosynthesis ("translation, ribosomal structure and biogenesis") with the most prominent ribosomal proteins L and S originating from the bacterial families Prevotellaceae, Clostridiaceae, Lactobacillaceae, Lachnospiraceae, Ruminococcaceae, and Selenomonadaceae. Other abundant PGs belonged to the category "carbohydrate transport and metabolism" (3-7\%), among them many proteins involved in glycolysis and gluconeogenesis, and "energy production and conversion" (3-5\%), including proteins linked to the ATP synthase and NADH dehydrogenase complex. Moreover, proteins belonging to the functional category "post-translational modification, protein turnover, chaperones" (3-4\%), "cell motility" (2-4\%) and "amino acid transport and metabolism" (2-3\%) were frequently identified (Figure 5, Figure S2). A detailed list of all and frequently found PGs, their taxonomical origin and functional assignment are provided in Tables S6-S8, respectively. In contrast to the time-related dynamics in the taxonomic composition of the microbiome, we observed overlaps of the NMDS clusters based on functional protein annotations (Figure 3C). In conclusion, our data suggest that albeit the taxonomic composition of the microbiome alters along the time course of the experiment, its functional potential remains rather stable compared to the taxonomy (Figure 5, Figure S2), indicating a functional redundancy among microbiome members, as proposed by others (e.g., [11]). 
d00

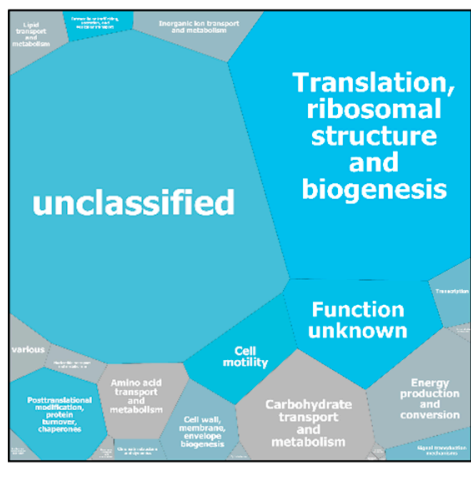

$\mathrm{d} 21$

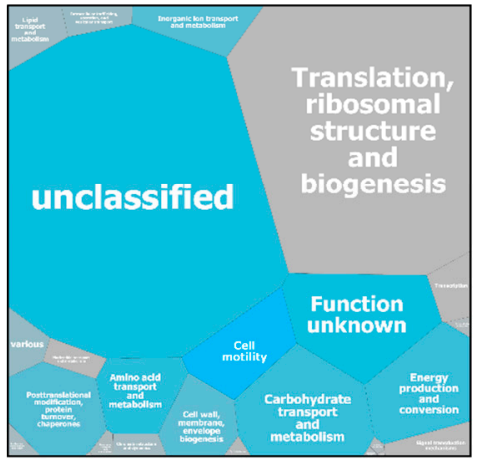

$\min$. d04

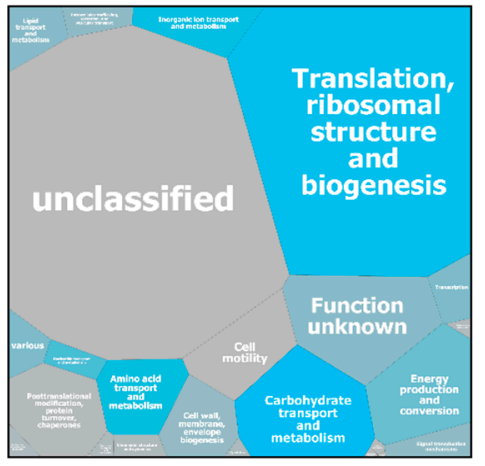

$\mathrm{d} 25$

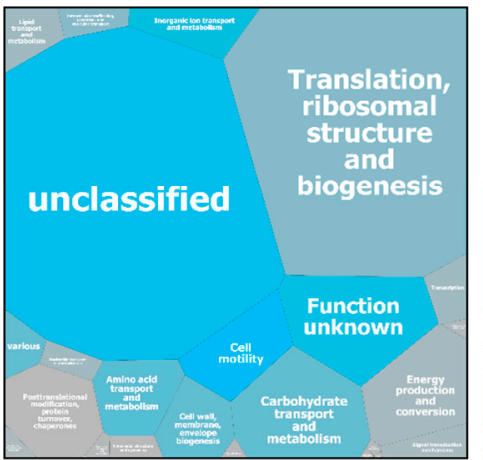

relative abundance d07

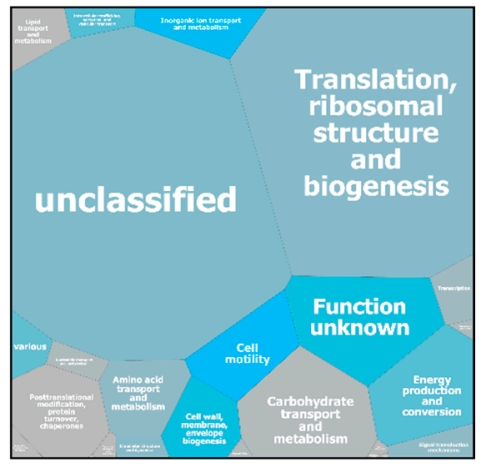

d30

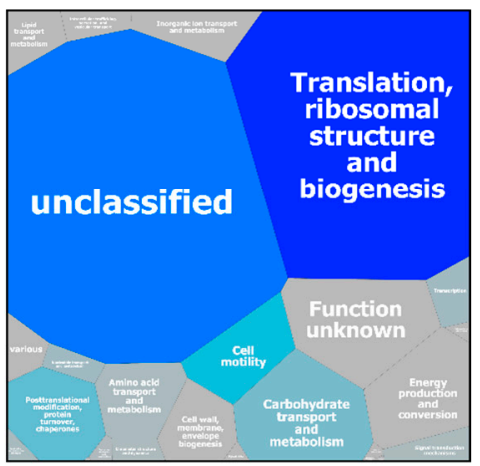

$+3 \%$

Figure 5. Voronoi Treemap illustrating functions (based on eggNOG categories) of the identified PGs from swine feces collected over 30 days. Field size represents the average over all samples minimal relative abundance over time of the corresponding category. The grey color represents the minimum expression of a functional category; dark blue fields indicate at maximum an increase of $3 \%$ in the relative abundance of the PGs at the sampling days compared to the minimum.

To identify important metabolites and to complement the metaproteomics dataset, metabolome analyses were performed. Microbial metabolites are known to affect host metabolism [71,72] and immune system [73-76] and can thus play a significant role in the health status of the host. Using ${ }^{1} \mathrm{H}-\mathrm{NMR}$ and GC-MS 70 different metabolites were identified (Table 4). These cover a broad spectrum of metabolic intermediates, production of which seemed to be triggered by the complex host-microbiota interplay. Among the frequently identified compounds were: metabolites of the central carbon metabolism (e.g., glucose, succinate or malate), amino acids (e.g., lysine and valine, aspartate, glutamate, glycine and tyrosine), as well as palmitate and 3-hydroxybutyrate. Lysine and valine were described as preferred substrates for gut bacteria [77]. In addition, large quantities of ornithine, methionine and arginine were found, which could be catabolized in polyamines [78]. Polyamines are involved in enhancing the integrity of the intestinal barrier and are responsible for maintaining, rapid turnover and proliferation of intestinal epithelial cells. Apart from this, polyamines stimulate the production of intercellular junction proteins, which regulate the epithelial barrier function cells [79]. Interestingly, Löser and colleagues [80] have demonstrated an important role of intestinal polyamine pools during the postnatal development of the gastrointestinal tract.

Metabolite concentrations determined from feces can be regarded as rough estimation but they do not reflect the exact metabolite levels present in the colon [81]. Due to the dynamic nature of metabolites and the fact that their production is affected by internal and external factors (e.g., enzyme activity, storage or analysis method) [82], metabolome analysis revealed larger differences between the individual animals and sampling days compared to the consistent profile of functional metaproteome (Figure 3C,D). Visual overlay of metaproteomics and metabolomics data provided a detailed overview 
of the metabolic activities in the microbiome (Figure S3). Remarkably, nearly all metabolites could be matched to pathways that were postulated to be active based on our metaproteomic data using the online tool IPath3 [83].

SCFAs, central metabolites that are exclusively synthesized by different microbiome members, are known to affect the health status of the host (reviewed in, e.g., Koh et al. [72]). They have been implicated in host cell proliferation, epithelial cell integrity, histone (de-)acetylation, and G-protein coupled receptor 43 (GPR43) activation (reviewed in, e.g., Venegas et al. [84]). Our metabolome analysis revealed acetate as the most abundant SCFA, which has been also observed in various other studies (e.g., [11,23,78]). Furthermore, butyrate and propionate were detected in high concentrations (Figure 6). The detected amounts of SCFAs were comparable to a study by Heinritz and colleagues, that investigated the effects of different diets on the microbiome composition and metabolite production in 12-week-old pigs [11]. There were several studies [85-88] that measured higher SCFA concentrations in gastrointestinal tract samples from pigs. However, it is important to note that some of these studies $[85,87,88]$ used digesta samples from different gastrointestinal sections instead of fecal samples for SCFA measurement. It was recently shown that fecal samples have lower concentrations of SCFAs, due to the fact that $95 \%$ of the produced SCFAs were absorbed during the flow of contents through the gastrointestinal tract. Therefore, feces were known to have lower concentrations of SCFAs than the digesta of intestinal sections [89].

A

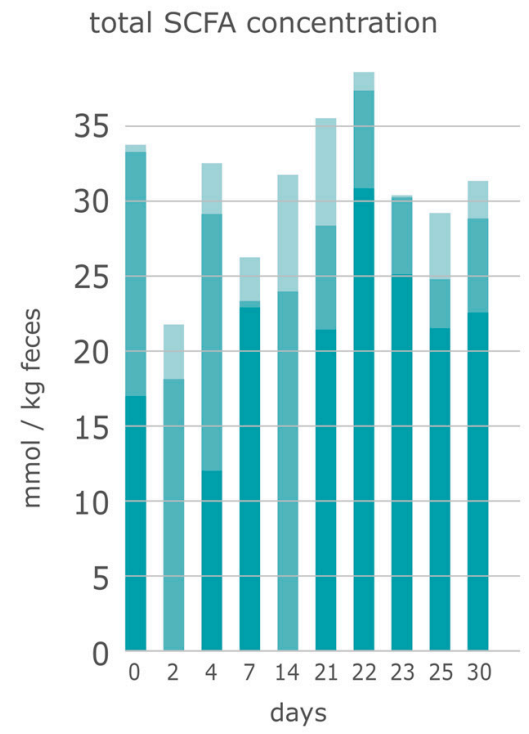

B SCFA concentrations

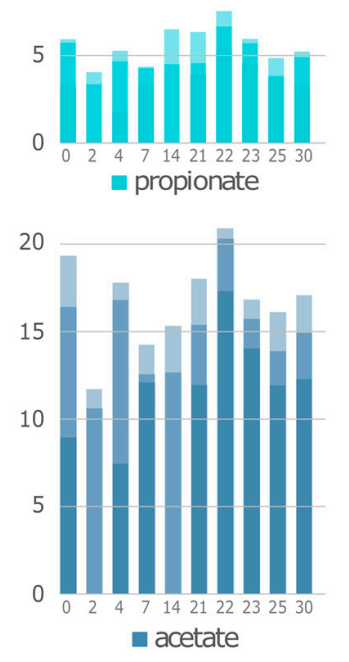

Figure 6. Total amount of all SCFAs (A) and concentrations of acetate, propionate, butyrate, valerate, isobutyrate, and isovalerate (B) of swine fecal samples from ${ }^{1} \mathrm{H}-\mathrm{NMR}$ analysis over 30 days. Y-axes: SCFA concentration in $\mathrm{mmol} / \mathrm{kg}$ feces; $\mathrm{X}$-axes: sampling day.

In good accordance to the metabolome data, our metaproteomics study identified several key-enzymes of the SCFA production pathways, i.e., acetyl-CoA acetyltransferase, acetyl-CoA carboxylase, methylmalonyl-CoA mutase, butyrate kinase, and acetate kinase. These enzymes were expressed by different members of the orders Clostridiales, Bacteroidales, Selenomonadales, Veillonellales, and Acidaminococcales. Especially the orders Clostridiales (e.g., Lachnospiraceae and Ruminococcaceae) and Bacteroidales (e.g., Bacteroidaceae and Prevotellaceae) were known as main SCFA producers in the gut [20,72]. Albeit the amounts of acetate, propionate, butyrate and valerate reached a slight maximum at day 22 before decreasing, rather stable SCFA concentrations were observed during 30 days (Figure 6). Notably, we detected an increased abundance of the families Streptococcaceae and Spirochaetaceae while acetate and propionate were measured in higher concentrations. 


\section{Conclusions}

In conclusion, we developed an integrated multi-omics protocol for the analysis of porcine feces, which enabled a contact-free, high-throughput homogenization of the heterogenous fecal sample, while keeping it frozen. The homogeneous fecal powder was easily divided for the use of specialized extraction protocols for the individual omics techniques. Furthermore, we found that the taxonomic composition of feces and colon rather congruent. Therefore, we suggest that feces could be used as minimal-invasive proxy for the colon in future analyses of the gastrointestinal tract.

Applying this protocol in a typical biomedical experiment revealed congruent dynamics in microbiome structure and function but also large conformity between the different pigs. Taxonomic analysis showed a dynamic microbiome composition, which is not surprising given the successional dynamics of eight-week-old piglets over 30 days. Consequently, these high microbiome dynamics have to be considered in the design of biomedical experiments using swine.

Functional analysis via metaproteomics revealed low variability between the individual animals and at the sampling days. Through this observation, infection-related changes in the microbiome could be detected in further experiments. Integration of metaproteomic and metabolomic data resulted in large coverage of the metabolic pathways. Because main functional assignments and metabolites, such as SCFAs, were more or less stable, we suggest, that these findings point towards functional redundancy during the natural development of the individual intestinal microbiota. To verify this hypothesis, we will analyze the influence of time and infection on the functional potential of the gastrointestinal microbiome of swine in further infection studies.

Our study and the resulting multi-omics sample processing pipeline can pave the way for a more detailed analysis in the context of future porcine infection experiments with swine pathogenic microorganisms, e.g., influenza A virus or Streptococcus suis, as well as any other event that alters the gastrointestinal microbiome (e.g., after weaning or dietary changes). Further improvements could be beneficial for the presented approach, such as the use of additional replicates, to enable more robust statistical analyses. Furthermore, the use of metagenomics or transcriptomics instead of 16S rRNA genes to create ecosystem-specific databases for the analysis of the metaproteome would likely increase the number of identified protein groups, and might also reduce inconsistencies in the taxonomic classification between nucleic acid and protein group based profiles.

Supplementary Materials: The following are available online at http:/www.mdpi.com/2076-2607/8/12/1887/s1. Figure S1: Heatmap displaying fold-change (mean amount day x/mean amount over 30 days) of detected metabolites in pig feces by GC-MS and ${ }^{1} \mathrm{H}-\mathrm{NMR}$ spectroscopy. Dark blue color indicates an increased fold change of 2.5, while white color represents a decrease in the fold change to 0.3. Figure S2: Assignment of identified PGs from swine feces to functional categories based on eggnog $(n=3$ for sampling day $0,7,21,25$ and $30, n=2$ for sampling day 4). For the functional analysis of the metaproteome all identified PGs were considered, including unclassified PGs and PGs with unknown function. Figure S3: Integration of metaproteome and metabolite profiles of swine feces. Blue lines highlight the identified proteins of corresponding pathways. Detected metabolites were grouped in the categories SCFAs (teal), fatty acids (dark green), carbon core metabolism (purple), amino acids (orange), amino acid degradation (yellow), various (black), and depicted as spots. Table S1: Amount of isolated DNA from swine feces using different extraction protocols. Table S2: Average protein concentration from swine feces after employing different protein extraction protocols. Table S3: Total number of identified protein groups from swine feces at the corresponding sampling days. Table S4: nmds data 16S metaprot metabolome. Table S5: data heatmap intestinals. Table S6: frequent families. Table S7: frequent proteins. Table S8: prophane output all protein groups.

Author Contributions: Conceptualization, L.C.G., A.M., D.S., M.L., T.U. and K.R.; methodology, L.C.G., A.M., D.S., C.W. and B.K.; software, S.F. and J.B.; data curation, L.C.G., A.M. and D.S.; formal analysis, L.C.G., A.M., D.S., H.W., J.B. and S.F.; funding acquisition, T.U. and K.R.; investigation, L.C.G., A.M., D.S., H.W. and J.B.; resources, T.S., C.K., C.S., C.W., K.M., B.K., D.B. and M.L. visualization, L.C.G., A.M. and J.B.; writing-original draft, L.C.G., A.M., D.S., M.L., T.U. and K.R.; writing-review and editing, L.C.G., A.M., D.S., T.S., C.K., C.S., H.W., C.W., K.M., B.K., S.F., J.B., D.B., M.L., T.U. and K.R. The following are members of the KoInfekt Study Group (all contributed to resources): T.M. (Thomas Mettenleiter), M.B. (Martin Beer), U.B. (Ulrike Blohm), D.H. (Dirk Höper), B.K. (Bernd Köllner), A.S. (Alexander Schäfer), J.S. (Julia Sehl) (all Friedrich-Loeffler-Institut, Insel Riems, Germany) and Reiner Ulrich (R.U.) (University of Leipzig, Institute of Veterinary Pathology, Faculty of Veterinary Medicine, Leipzig, Germany). All authors have read and agreed to the published version of the manuscript. 
Funding: This research was funded by Federal Excellence Initiative of Mecklenburg Western Pomerania and European Social Fund (ESF) Grant KoInfekt (ESF_14-BM-A55-0006_16, ESF_14-BM-A55-0013_16, ESF_14-BM-A55-0005_16, ESF_14-BM-A55-0002_16, ESF_14-BM-A55-0008_16, ESF_14-BM-A55-0010_16).

Acknowledgments: The authors want to acknowledge all partners of the collaborative project "KoInfekt", that were involved in the Influenza A Virus H1N1 infection trail and made it possible to evaluate the potential of swine as a biomedical model regarding the impact of the infection on host fitness, physiology, immune response and respiratory as well as intestinal microbiomes. Furthermore, we are grateful to Daniela Zühlke and Jana Bull for their support. We thank Kerstin Kerstel, Thomas Möritz, Nicole Sinkwitz, Lukas Steinke, Ralf Henkel und Christian Loth from the Friedrich-Loeffler-Institut (Insel Riems) for the provided animal samples. We acknowledge support for the Article Processing Charge from the DFG (German Research Foundation, 393148499) and the Open Access Publication Fund of the University of Greifswald.

Conflicts of Interest: The authors declare no conflict of interest.

\section{References}

1. Kau, A.L.; Ahern, P.P.; Griffin, N.W.; Goodman, A.L.; Gordon, J.I. Human nutrition, the gut microbiome and the immune system: Envisioning the future. Nat. Cell Biol. 2011, 474, 327-336. [CrossRef]

2. Bäckhed, F.; Ding, H.; Wang, T.; Hooper, L.V.; Koh, G.Y.; Nagy, A.; Semenkovich, C.F.; Gordon, J.I. The gut microbiota as an environmental factor that regulates fat storage. Proc. Natl. Acad. Sci. USA 2004, 101, 15718-15723. [CrossRef] [PubMed]

3. Hooper, L.V. Commensal Host-Bacterial Relationships in the Gut. Science 2001, 292, 1115-1118. [CrossRef] [PubMed]

4. DiBaise, J.K.; Frank, D.N.; Mathur, R. Impact of the Gut Microbiota on the Development of Obesity: Current Concepts. Am. J. Gastroenterol. Suppl. 2012, 1, 22-27. [CrossRef]

5. Cani, P.D.; Bibiloni, R.; Knauf, C.; Waget, A.; Neyrinck, A.M.; Delzenne, N.M.; Burcelin, R. Changes in Gut Microbiota Control Metabolic Endotoxemia-Induced Inflammation in High-Fat Diet-Induced Obesity and Diabetes in Mice. Diabetes 2008, 57, 1470-1481. [CrossRef]

6. Tlaskalová-Hogenová, H.; Stěpánková, R.; Kozáková, H.; Hudcovic, T.; Vannucci, L.; Tučková, L.; Rossmann, P.; Hrnčíř, T.; Kverka, M.; Zákostelská, Z.; et al. The role of gut microbiota (commensal bacteria) and the mucosal barrier in the pathogenesis of inflammatory and autoimmune diseases and cancer: Contribution of germ-free and gnotobiotic animal models of human diseases. Cell. Mol. Immunol. 2011, 8, 110-120. [CrossRef]

7. Khor, B.; Gardet, A.; Xavier, R.J. Genetics and pathogenesis of inflammatory bowel disease. Nat. Cell Biol. 2011, 474, 307-317. [CrossRef]

8. Sartor, R.B. Microbial Influences in Inflammatory Bowel Diseases. Gastroenterology 2008, 134, 577-594. [CrossRef]

9. Littman, D.R.; Pamer, E.G. Role of the Commensal Microbiota in Normal and Pathogenic Host Immune Responses. Cell Host Microbe 2011, 10, 311-323. [CrossRef]

10. De Rodas, B.; Youmans, B.P.; Danzeisen, J.L.; Tran, H.; Johnson, T.J. Microbiome profiling of commercial pigs from farrow to finish. J. Anim. Sci. 2018, 96, 1778-1794. [CrossRef]

11. Heinritz, S.N.; Weiss, E.; Eklund, M.; Aumiller, T.; Louis, S.; Rings, A.; Messner, S.; Camarinha-Silva, A.; Seifert, J.; Bischoff, S.C.; et al. Intestinal Microbiota and Microbial Metabolites Are Changed in a Pig Model Fed a High-Fat/Low-Fiber or a Low-Fat/High-Fiber Diet. PLoS ONE 2016, 11, e0154329. [CrossRef] [PubMed]

12. Justice, M.; Dhillon, P. Using the mouse to model human disease: Increasing validity and reproducibility. Dis. Model. Mech. 2016, 9, 101-103. [CrossRef] [PubMed]

13. Nguyen, T.L.A.; Vieira-Silva, S.; Liston, A.; Raes, J. How informative is the mouse for human gut microbiota research? Dis. Model. Mech. 2015, 8, 1-16. [CrossRef] [PubMed]

14. Mestas, J.; Hughes, C.C.W. Of Mice and Not Men: Differences between Mouse and Human Immunology. J. Immunol. 2004, 172, 2731-2738. [CrossRef]

15. Meurens, F.; Summerfield, A.; Nauwynck, H.; Saif, L.; Gerdts, V. The pig: A model for human infectious diseases. Trends Microbiol. 2012, 20, 50-57. [CrossRef]

16. Niemann, H.; Petersen, B. The production of multi-transgenic pigs: Update and perspectives for xenotransplantation. Transgenic Res. 2016, 25, 361-374. [CrossRef] 
17. Wang, M.; Donovan, S. Human Microbiota-Associated Swine: Current Progress and Future Opportunities. ILAR J. 2015, 56, 63-73. [CrossRef]

18. Isaacson, R.E.; Kim, H.B. The intestinal microbiome of the pig. Anim. Heal. Res. Rev. 2012, 13, $100-109$. [CrossRef]

19. Holman, D.B.; Brunelle, B.W.; Trachsel, J.; Allen, H.K. Meta-analysis To Define a Core Microbiota in the Swine Gut. mSystems 2017, 2, e00004-17. [CrossRef]

20. Kim, H.B.; Borewicz, K.; White, B.A.; Singer, R.S.; Sreevatsan, S.; Tu, Z.J.; Isaacson, R.E. Longitudinal investigation of the age-related bacterial diversity in the feces of commercial pigs. Vet. Microbiol. 2011, 153, 124-133. [CrossRef]

21. Arumugam, M.; Raes, J.; Pelletier, E.; Le Paslier, D.; Yamada, T.; Mende, D.R.; Fernandes, G.R.; Tap, J.; Bruls, T.; Batto, J.M.; et al. Enterotypes of the human gut microbiome. Nature 2011, 473, 174-180. [CrossRef] [PubMed]

22. Ley, R.E.; Bäckhed, F.; Turnbaugh, P.; Lozupone, C.A.; Knight, R.D.; Gordon, J.I. Obesity alters gut microbial ecology. Proc. Natl. Acad. Sci. USA 2005, 102, 11070-11075. [CrossRef] [PubMed]

23. Wang, J.; Lang, T.; Shen, J.; Dai, J.; Tian, L.; Wang, X. Core Gut Bacteria Analysis of Healthy Mice. Front. Microbiol. 2019, 10, 887. [CrossRef] [PubMed]

24. Roume, H.; Muller, E.E.L.; Cordes, T.; Renaut, J.; Hiller, K.; Wilmes, P. A biomolecular isolation framework for eco-systems biology. ISME J. 2013, 7, 110-121. [CrossRef]

25. Heintz-Buschart, A.; May, P.; Laczny, C.C.; Lebrun, L.A.; Bellora, C.; Krishna, A.; Wampach, L.; Schneider, J.G.; Hogan, A.; De Beaufort, C.; et al. Integrated multi-omics of the human gut microbiome in a case study of familial type 1 diabetes. Nat. Microbiol. 2017, 2, 16180. [CrossRef]

26. Deusch, S.; Seifert, J. Catching the tip of the iceberg-Evaluation of sample preparation protocols for metaproteomic studies of the rumen microbiota. Proteomics 2015, 15, 3590-3595. [CrossRef]

27. Tröscher-Mußotter, J.; Tilocca, B.; Stefanski, V.; Seifert, J. Analysis of the Bacterial and Host Proteins along and across the Porcine Gastrointestinal Tract. Proteomes 2019, 7, 4. [CrossRef]

28. Yang, L.-N.; Pu, J.-C.; Liu, L.-X.; Wang, G.-W.; Zhou, X.-Y.; Zhang, Y.-Q.; Liu, Y.-Y.; Xie, P. Integrated Metabolomics and Proteomics Analysis Revealed Second Messenger System Disturbance in Hippocampus of Chronic Social Defeat Stress Rat. Front. Neurosci. 2019, 13, 247. [CrossRef]

29. Kan, J.; Hanson, T.E.; Ginter, J.M.; Wang, K.; Chen, F. Metaproteomic analysis of Chesapeake Bay microbial communities. Saline Syst. 2005, 1, 7. [CrossRef]

30. Erickson, A.R.; Cantarel, B.L.; Lamendella, R.; Darzi, Y.; Mongodin, E.F.; Pan, C.; Shah, M.; Halfvarson, J.; Tysk, C.; Henrissat, B.; et al. Integrated metagenomics/metaproteomics reveals human host-microbiota signatures of Crohn's disease. PLoS ONE 2012, 7, e49138. [CrossRef]

31. Kolmeder, C.; De Been, M.; Nikkilä, J.; Ritamo, I.; Mättö, J.; Valmu, L.; Salojärvi, J.; Palva, A.; Salonen, A.; De Vos, W.M. Comparative Metaproteomics and Diversity Analysis of Human Intestinal Microbiota Testifies for Its Temporal Stability and Expression of Core Functions. PLoS ONE 2012, 7, e29913. [CrossRef] [PubMed]

32. Schwaiger, T.; Sehl, J.; Karte, C.; Schäfer, A.; Hühr, J.; Mettenleiter, T.C.; Schröder, C.; Köllner, B.; Ulrich, R.; Blohm, U. Experimental H1N1pdm09 infection in pigs mimics human seasonal influenza infections. PLoS ONE 2019, 14, e0222943. [CrossRef] [PubMed]

33. Berry, D.; Schwab, C.; Milinovich, G.; Reichert, J.; Ben Mahfoudh, K.; Decker, T.; Engel, M.; Hai, B.; Hainzl, E.; Heider, S.; et al. Phylotype-level 16S rRNA analysis reveals new bacterial indicators of health state in acute murine colitis. ISME J. 2012, 6, 2091-2106. [CrossRef] [PubMed]

34. Parada, A.E.; Needham, D.M.; Fuhrman, J.A. Every base matters: Assessing small subunit rRNA primers for marine microbiomes with mock communities, time series and global field samples. Environ. Microbiol. 2015, 18, 1403-1414. [CrossRef]

35. Apprill, A.; McNally, S.; Parsons, R.; Weber, L. Minor revision to V4 region SSU rRNA 806R gene primer greatly increases detection of SAR11 bacterioplankton. Aquat. Microb. Ecol. 2015, 75, 129-137. [CrossRef]

36. R Core Team. R: A Language and Environment for Statistical Computing; R Foundation for Statistical Computing: Vienna, Austria, 2019; Available online: http://www.R-project.org/ (accessed on 7 January 2020).

37. Callahan, B.J.; McMurdie, P.J.; Rosen, M.J.; Han, A.W.; A Johnson, A.J.; Holmes, S.P. DADA2: High-resolution sample inference from Illumina amplicon data. Nat. Methods 2016, 13, 581-583. [CrossRef] 
38. Quast, C.; Pruesse, E.; Yilmaz, P.; Gerken, J.; Schweer, T.; Yarza, P.; Peplies, J.; Glöckner, F.O. The SILVA ribosomal RNA gene database project: Improved data processing and web-based tools. Nucleic Acids Res. 2013, 41, D590-D596. [CrossRef]

39. Chomczynski, P. A reagent for the single-step simultaneous isolation of RNA, DNA and proteins from cell and tissue samples. Biotechniques 1993, 15, 532-537.

40. Smith, P.; Krohn, R.; Hermanson, G.; Mallia, A.; Gartner, F.; Provenzano, M.; Fujimoto, E.; Goeke, N.; Olson, B.; Klenk, D. Measurement of protein using bicinchoninic acid. Anal. Biochem. 1985, 150, 76-85. [CrossRef]

41. Wiechelman, K.J.; Braun, R.D.; Fitzpatrick, J.D. Investigation of the bicinchoninic acid protein assay: Identification of the groups responsible for color formation. Anal. Biochem. 1988, 175, 231-237. [CrossRef]

42. Kessler, R.J.; Fanestil, D.D. Interference by lipids in the determination of protein using bicinchoninic acid. Anal. Biochem. 1986, 159, 138-142. [CrossRef]

43. Brown, R.E.; Jarvis, K.L.; Hyland, K.J. Protein measurement using bicinchoninic acid: Elimination of interfering substances. Anal. Biochem. 1989, 180, 136-139. [CrossRef]

44. Neuhoff, V.; Arold, N.; Taube, D.; Ehrhardt, W. Improved staining of proteins in polyacrylamide gels including isoelectric focusing gels with clear background at nanogram sensitivity using Coomassie Brilliant Blue G-250 and R-250. Electrophoresis 1988, 9, 255-262. [CrossRef] [PubMed]

45. Teeling, H.; Fuchs, B.M.; Becher, D.; Klockow, C.; Gardebrecht, A.; Bennke, C.M.; Kassabgy, M.; Huang, S.; Mann, A.J.; Waldmann, J.; et al. Substrate-Controlled Succession of Marine Bacterioplankton Populations Induced by a Phytoplankton Bloom. Science 2012, 336, 608-611. [CrossRef] [PubMed]

46. Lassek, C.; Burghartz, M.; Chaves-Moreno, D.; Otto, A.; Hentschker, C.; Fuchs, S.; Bernhardt, J.; Jauregui, R.; Neubauer, R.; Becher, D.; et al. A Metaproteomics Approach to Elucidate Host and Pathogen Protein Expression during Catheter-Associated Urinary Tract Infections (CAUTIs). Mol. Cell. Proteom. 2015, 14, 989-1008. [CrossRef] [PubMed]

47. Perez-Riverol, Y.; Csordas, A.; Bai, J.; Bernal-Llinares, M.; Hewapathirana, S.; Kundu, D.J.; Inuganti, A.; Griss, J.; Mayer, G.; Eisenacher, M.; et al. The PRIDE database and related tools and resources in 2019: Improving support for quantification data. Nucleic Acids Res. 2019, 47, D442-D450. [CrossRef] [PubMed]

48. Howe, E.; Holton, K.; Nair, S.; Schlauch, D.; Sinha, R.; Quackenbush, J. MeV: MultiExperiment Viewer. In Biomedical Informatics for Cancer Research; Springer: Berlin/Heidelberg, Germany, 2010; pp. 267-277.

49. Schultz, D.; Schlüter, R.; Gerth, U.; Lalk, M. Metabolic Perturbations in a Bacillus subtilis clpP Mutant during Glucose Starvation. Metabolites 2017, 7, 63. [CrossRef]

50. Dörries, K.; Schlueter, R.; Lalk, M. Impact of Antibiotics with Various Target Sites on the Metabolome of Staphylococcus aureus. Antimicrob. Agents Chemother. 2014, 58, 7151-7163. [CrossRef]

51. Deda, O.; Chatziioannou, A.C.; Fasoula, S.; Palachanis, D.; Raikos, N.; Theodoridis, G.A.; Gika, H.G. Sample preparation optimization in fecal metabolic profiling. J. Chromatogr. B 2017, 1047, 115-123. [CrossRef]

52. Matysik, S.; Le Roy, C.I.; Liebisch, G.; Claus, S.P. Metabolomics of fecal samples: A practical consideration. Trends Food Sci. Technol. 2016, 57, 244-255. [CrossRef]

53. Smirnov, K.S.; Maier, T.V.; Walker, A.; Heinzmann, S.S.; Forcisi, S.; Martinez, I.; Walter, J.; Schmitt-Kopplin, P. Challenges of metabolomics in human gut microbiota research. Int. J. Med Microbiol. 2016, 306, 266-279. [CrossRef] [PubMed]

54. Wylezich, C.; Papa, A.; Beer, M.; Höper, D. A Versatile Sample Processing Workflow for Metagenomic Pathogen Detection. Sci. Rep. 2018, 8, 13108. [CrossRef] [PubMed]

55. Wang, X.; Tsai, T.; Deng, F.; Wei, X.; Chai, J.; Knapp, J.; Apple, J.; Maxwell, C.V.; Lee, J.A.; Li, Y.; et al. Longitudinal investigation of the swine gut microbiome from birth to market reveals stage and growth performance associated bacteria. Microbiome 2019, 7, 109. [CrossRef]

56. Kuhn, R.; Benndorf, D.; Rapp, E.; Reichl, U.; Palese, L.; Pollice, A. Metaproteome analysis of sewage sludge from membrane bioreactors. Proteomics 2011, 11, 2738-2744. [CrossRef] [PubMed]

57. Tanca, A.; Palomba, A.; Pisanu, S.; Deligios, M.; Fraumene, C.; Manghina, V.; Pagnozzi, D.; Addis, M.F.; Uzzau, S. A straightforward and efficient analytical pipeline for metaproteome characterization. Microbiome 2014, 2, 49. [CrossRef]

58. Wu, J.; An, Y.; Yao, J.; Wang, Y.; Tang, H. An optimised sample preparation method for NMR-based faecal metabonomic analysis. Analyst 2010, 135, 1023-1030. [CrossRef] 
59. Gao, X.; Pujos-Guillot, E.; Martin, J.-F.; Galan, P.; Juste, C.; Jia, W.; Sebedio, J.-L. Metabolite analysis of human fecal water by gas chromatography/mass spectrometry with ethyl chloroformate derivatization. Anal. Biochem. 2009, 393, 163-175. [CrossRef]

60. Tan, S.C.; Chong, C.W.; Yap, I.K.S.; Thong, K.L.; Teh, C.S.J. Comparative assessment of faecal microbial composition and metabonome of swine, farmers and human control. Sci. Rep. 2020, 10, 8997. [CrossRef]

61. Zhang, D.; Liu, H.; Wang, S.; Zhang, W.; Wang, J.; Tian, H.; Wang, Y.; Ji, H. Fecal Microbiota and Its Correlation With Fatty Acids and Free Amino Acids Metabolism in Piglets After a Lactobacillus Strain Oral Administration. Front. Microbiol. 2019, 10, 785. [CrossRef]

62. Wen, X.; Wang, L.; Zheng, C.; Yang, X.; Ma, X.; Wu, Y.; Chen, Z.; Jiang, Z. Fecal scores and microbial metabolites in weaned piglets fed different protein sources and levels. Anim. Nutr. 2018, 4, 31-36. [CrossRef]

63. Leser, T.D.; Amenuvor, J.Z.; Jensen, T.K.; Lindecrona, R.H.; Boye, M.; Møller, K. Culture-Independent Analysis of Gut Bacteria: The Pig Gastrointestinal Tract Microbiota Revisited. Appl. Environ. Microbiol. 2002, 68, 673-690. [CrossRef] [PubMed]

64. Weiss, E.; Aumiller, T.; Spindler, H.K.; Rosenfelder, P.; Eklund, M.; Witzig, M.; Jørgensen, H.; Knudsen, K.E.B.; Mosenthin, R. Wheat and barley differently affect porcine intestinal microbiota. J. Sci. Food Agric. 2015, 96, 2230-2239. [CrossRef] [PubMed]

65. Le Sciellour, M.; Renaudeau, D.; Zemb, O. Longitudinal Analysis of the Microbiota Composition and Enterotypes of Pigs from Post-Weaning to Finishing. Microorganisms 2019, 7, 622. [CrossRef]

66. Heinritz, S.N.; Mosenthin, R.; Weiss, E. Use of pigs as a potential model for research into dietary modulation of the human gut microbiota. Nutr. Res. Rev. 2013, 26, 191-209. [CrossRef] [PubMed]

67. Stoddard, S.F.; Smith, B.J.; Hein, R.; Roller, B.R.; Schmidt, T.M. rrnDB: Improved tools for interpreting rRNA gene abundance in bacteria and archaea and a new foundation for future development. Nucleic Acids Res. 2015, 43, D593-D598. [CrossRef] [PubMed]

68. Looft, T.; Allen, H.K.; Cantarel, B.L.; Levine, U.Y.; O Bayles, D.; Alt, D.P.; Henrissat, B.; Stanton, T.B. Bacteria, phages and pigs: The effects of in-feed antibiotics on the microbiome at different gut locations. ISME J. 2014, 8, 1566-1576. [CrossRef] [PubMed]

69. Deusch, S.; Tilocca, B.; Camarinha-Silva, A.; Seifert, J. News in livestock research-Use of Omics-technologies to study the microbiota in the gastrointestinal tract of farm animals. Comput. Struct. Biotechnol. J. 2015, 13, 55-63. [CrossRef]

70. Powell, S.; Szklarczyk, D.; Trachana, K.; Roth, A.; Kuhn, M.; Muller, J.; Arnold, R.; Rattei, T.; Letunic, I.; Doerks, T; et al. eggNOG v3.0: Orthologous groups covering 1133 organisms at 41 different taxonomic ranges. Nucleic Acids Res. 2012, 40, D284-D289. [CrossRef]

71. Rowland, I.; Gibson, G.R.; Heinken, A.; Scott, K.P.; Swann, J.; Thiele, I.; Tuohy, K.M. Gut microbiota functions: Metabolism of nutrients and other food components. Eur. J. Nutr. 2018, 57, 1-24. [CrossRef]

72. Koh, A.; De Vadder, F.; Kovatcheva-Datchary, P.; Bäckhed, F. From Dietary Fiber to Host Physiology: Short-Chain Fatty Acids as Key Bacterial Metabolites. Cell 2016, 165, 1332-1345. [CrossRef]

73. Rooks, M.G.; Garrett, W.S. Gut microbiota, metabolites and host immunity. Nat. Rev. Immunol. 2016, 16, 341-352. [CrossRef] [PubMed]

74. Blacher, E.; Levy, M.; Tatirovsky, E.; Elinav, E. Microbiome-Modulated Metabolites at the Interface of Host Immunity. J. Immunol. 2017, 198, 572-580. [CrossRef] [PubMed]

75. Postler, T.S.; Ghosh, S. Understanding the Holobiont: How Microbial Metabolites Affect Human Health and Shape the Immune System. Cell Metab. 2017, 26, 110-130. [CrossRef] [PubMed]

76. Kim, C.H. Immune regulation by microbiome metabolites. Immunology 2018, 154, 220-229. [CrossRef] [PubMed]

77. Macfarlane, G.T.; Allison, C.; Gibson, S.A.W.; Cummings, J.H. Contribution of the microflora to proteolysis in the human large intestine. J. Appl. Bacteriol. 1988, 64, 37-46. [CrossRef]

78. Miller-Fleming, L.; Olin-Sandoval, V.; Campbell, K.; Ralser, M. Remaining Mysteries of Molecular Biology: The Role of Polyamines in the Cell. J. Mol. Biol. 2015, 427, 3389-3406. [CrossRef]

79. Liu, L.; Guo, X.; Rao, J.N.; Zou, T.; Xiao, L.; Yu, T.; Timmons, J.A.; Turner, D.J.; Wang, J.-Y. Polyamines regulate E-cadherin transcription through c-Myc modulating intestinal epithelial barrier function. Am. J. Physiol. Physiol. 2009, 296, C801-C810. [CrossRef]

80. Löser, C.; Eisel, A.; Harms, D.; Fölsch, U.R. Dietary polyamines are essential luminal growth factors for small intestinal and colonic mucosal growth and development. Gut 1999, 44, 12-16. [CrossRef] 
81. Besten, G.D.; Van Eunen, K.; Groen, A.K.; Venema, K.; Reijngoud, D.-J.; Bakker, B.M. The role of short-chain fatty acids in the interplay between diet, gut microbiota, and host energy metabolism. J. Lipid Res. 2013, 54, 2325-2340. [CrossRef]

82. Gil Quintero, A.; Siegel, D.; Permentier, H.; Reijngoud, D.-J.; Dekker, F.W.; Bischoff, R. Stability of energy metabolites-An often overlooked issue in metabolomics studies: A review. Electrophoresis 2015, 36, 2156-2169. [CrossRef]

83. Darzi, Y.; Letunic, I.; Bork, P.; Yamada, T. iPath3.0: Interactive pathways explorer v3. Nucleic Acids Res. 2018, 46, W510-W513. [CrossRef] [PubMed]

84. Parada Venegas, D.; de La Fuente, M.K.; Landskron, G.; González, M.J.; Quera, R.; Dijkstra, G.; Harmsen, H.J.M.; Faber, K.N.; Hermoso, M.A. Short Chain Fatty Acids (SCFAs)-Mediated Gut Epithelial and Immune Regulation and Its Relevance for Inflammatory Bowel Diseases. Front. Immunol. 2019, 10, 277. [CrossRef] [PubMed]

85. Canibe, N.; Steien, S.H.; Overland, M.; Jensen, B.B. Effect of K-diformate in starter diets on acidity, microbiota, and the amount of organic acids in the digestive tract of piglets, and on gastric alterations. J. Anim. Sci. 2001, 79, 2123-2133. [CrossRef] [PubMed]

86. Poulsen, A.-S.R.; de Jonge, N.; Nielsen, J.L.; Højberg, O.; Lauridsen, C.; Cutting, S.M.; Canibe, N. Impact of Bacillus spp. spores and gentamicin on the gastrointestinal microbiota of suckling and newly weaned piglets. PLoS ONE 2018, 13, e0207382. [CrossRef]

87. Guerra-Ordaz, A.A.; Molist, F.; Hermes, R.G.; Gómez de Segura, A.; La Ragione, R.M.; Woodward, M.J.; Tchorzewska, M.A.; Collins, J.W.; Pérez, J.F.; Martín-Orúe, S.M. Effect of inclusion of lactulose and Lactobacillus plantarum on the intestinal environment and performance of piglets at weaning. Anim. Feed. Sci. Technol. 2013, 185, 160-168. [CrossRef]

88. Molist, F.; de Segura, A.G.; Gasa, J.; Hermes, R.G.; Manzanilla, E.G.; Anguita, M.; Pérez, J.F. Effects of the insoluble and soluble dietary fibre on the physicochemical properties of digesta and the microbial activity in early weaned piglets. Anim. Feed. Sci. Technol. 2009, 149, 346-353. [CrossRef]

89. Sakata, T. Pitfalls in short-chain fatty acid research: A methodological review. Anim. Sci. J. 2019, 90, 3-13. [CrossRef]

Publisher's Note: MDPI stays neutral with regard to jurisdictional claims in published maps and institutional affiliations.

(C) 2020 by the authors. Licensee MDPI, Basel, Switzerland. This article is an open access article distributed under the terms and conditions of the Creative Commons Attribution (CC BY) license (http://creativecommons.org/licenses/by/4.0/). 